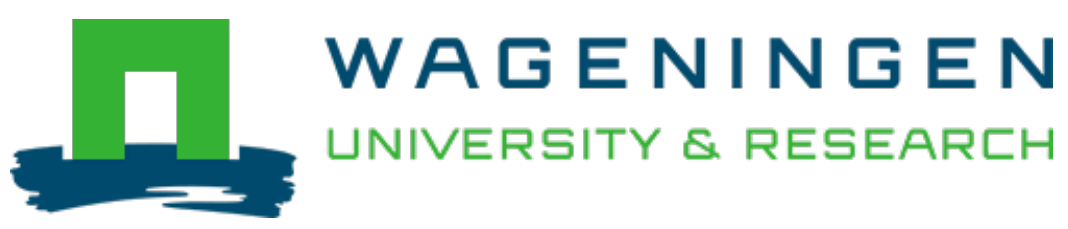

\title{
Exploring the relation between individual moral antecedents and entrepreneurial opportunity recognition for sustainable development
}

\author{
Journal of Cleaner Production \\ Ploum, Lisa; Blok, Vincent; Lans, Thomas; Omta, Onno \\ https://doi.org/10.1016/j.jclepro.2017.10.296
}

This article is made publicly available in the institutional repository of Wageningen University and Research, under the terms of article $25 \mathrm{fa}$ of the Dutch Copyright Act, also known as the Amendment Taverne. This has been done with explicit consent by the author.

Article 25 fa states that the author of a short scientific work funded either wholly or partially by Dutch public funds is entitled to make that work publicly available for no consideration following a reasonable period of time after the work was first published, provided that clear reference is made to the source of the first publication of the work.

This publication is distributed under The Association of Universities in the Netherlands (VSNU) 'Article $25 \mathrm{fa}$ implementation' project. In this project research outputs of researchers employed by Dutch Universities that comply with the legal requirements of Article $25 \mathrm{fa}$ of the Dutch Copyright Act are distributed online and free of cost or other barriers in institutional repositories. Research outputs are distributed six months after their first online publication in the original published version and with proper attribution to the source of the original publication.

You are permitted to download and use the publication for personal purposes. All rights remain with the author(s) and / or copyright owner(s) of this work. Any use of the publication or parts of it other than authorised under article $25 \mathrm{fa}$ of the Dutch Copyright act is prohibited. Wageningen University \& Research and the author(s) of this publication shall not be held responsible or liable for any damages resulting from your (re)use of this publication.

For questions regarding the public availability of this article please contact openscience.library@,wur.nl 


\title{
Exploring the relation between individual moral antecedents and entrepreneurial opportunity recognition for sustainable development
}

\author{
Lisa Ploum ${ }^{a}{ }^{*}$, Vincent Blok ${ }^{a}$, Thomas Lans ${ }^{b}$, Onno Omta ${ }^{a}$ \\ a Management Studies Group, School of Social Sciences, Wageningen University, The Netherlands \\ ${ }^{\mathrm{b}}$ Education and Competence Studies, School of Social Sciences, Wageningen University, The Netherlands
}

\section{A R T I C L E I N F O}

\section{Article history:}

Received 14 April 2017

Received in revised form

20 October 2017

Accepted 27 October 2017

Available online 27 October 2017

\section{Keywords:}

Opportunity recognition for sustainable development

Sustainable entrepreneurship

Moral competence

Pro-environmental behavior values

\begin{abstract}
A B S T R A C T
When dealing with complex value-driven problems such as sustainable development, individuals need to have values and norms that go beyond the appropriation of tangible business outcomes for themselves. This raises the question of the role played by individual moral antecedents in the entrepreneurial process of opportunity recognition for sustainable development. To answer this question, an exploratory empirical research design was used in which 96 would-be entrepreneurs were subjected to real-life decision-making processes in an online environment. The participants were guided through the process of opportunity recognition for sustainable development. Furthermore, they were subjected to several tests linked to individual moral antecedents. The mixed methods design used to analyze the results led to the conclusion that pro-environmental behavior values and moral competencies are important indicators of the ability to recognize opportunities for sustainable development. These results provide useful insights about relating moral antecedents to idea generation for sustainable development and can help researchers, higher education institutes, and sustainable entrepreneurs to further develop the concept of sustainable entrepreneurship and its underlying processes.
\end{abstract}

() 2017 Elsevier Ltd. All rights reserved.

\section{Introduction}

Sustainable development is nowadays perhaps the most prominent challenge for businesses. Climate change and the destruction of biodiversity demonstrate the negative and potentially deadly consequences these processes have for living species. As a response, the United Nations have developed the Sustainable Development Goals (SDGs) as a way to set an agenda to "end poverty, protect the planet, and ensure prosperity for all" (United Nations, 2016). Entrepreneurial action is increasingly seen as a promising way to preserve ecosystems, counteract climate change, reduce environmental degradation, improve agricultural practices, and maintain biodiversity (Dean and McMullen, 2007; Patzelt and Shepherd, 2011). The sustainable entrepreneur initiates those activities and processes that lead to the identification, evaluation, and exploitation of business opportunities in order to contribute to sustainable development (Schaltegger and Wagner, 2011; Patzelt and Shepherd, 2011). In line with this, more and more

\footnotetext{
* Corresponding author. Wageningen University, Management Studies, Hollandseweg 1, 6707 KN, Wageningen, P.O. Box 8130, The Netherlands.

E-mail address: lisa.ploum@wur.nl (L. Ploum).
}

entrepreneurs explicitly address one or more of the SDGs within their business practices. In particular, SDG 9 (industry, innovation and infrastructure) and SDG 12 (responsible consumption and production) seem to provide a wide range of opportunities for entrepreneurial action. However, SDG 7 (affordable and clean energy), SDG 11 (sustainable cities and communities), and SDG 13 (climate action) also provide stepping stones for sustainable entrepreneurs.

Opportunity recognition lies at the heart of entrepreneurship research, as the entrepreneurial process always starts with the identification of a potential business idea that could be explored and further developed into a new product, service, or process (Shane and Venkataraman, 2000). Therefore, the concept of opportunity has become central in entrepreneurship research (McMullen and Shepherd, 2006; Shane and Venkataraman, 2000; Davidsson, 2015). Nevertheless, on the conceptual front, there is still no consensus on what the concept of sustainable opportunity recognition entails. There has been considerable interest in studying the factors, processes, and dynamics that foster opportunity recognition (Baron and Ensley, 2006; Shane, 2000; Grégoire et al., 2010a). However, there is a lack of empirical studies that examine these factors, processes, and dynamics, as most research is still 
conceptual in nature (Dimov, 2007; Davidsson, 2015). Consequently, there is a growing gap between theorizing about opportunity recognition and research practices for studying the phenomenon. Another gap in the literature concerns the question of what discriminates sustainable entrepreneurship from conventional entrepreneurship and what role opportunity recognition plays in this distinction. On the one hand, sustainable entrepreneurship is seen as a way of generating competitive advantage by recognizing new sustainable business opportunities, resulting in new products, new methods of production, new markets, or new ways of organizing business processes (Patzelt and Shepherd, 2011). On the other hand, sustainability is a value-oriented and normative concept, as it addresses the question of how socialecological systems ought to be developed in order to make a trade-off between economic, social, and environmental aspects in business practices. Therefore, in contrast to regular opportunity recognition, the process of opportunity recognition for sustainable development includes individual moral antecedents such as ethical values and norms (Swart et al., 2004). The importance of moral values, such as altruism, in the sustainable entrepreneurial process was underpinned in the work of Patzelt and Shepherd (2011). Nevertheless, research on this relation has remained descriptive and conceptual ever since. In other fields related to sustainable entrepreneurship, for instance in the field of competencies for sustainable entrepreneurship, other value-oriented constructs (i.e. moral competencies) are considered as distinctive for sustainable entrepreneurship. Patzelt and Shepherd's (2011) conceptual model serves as a starting point for analyzing the relation between several different moral antecedents, as it is clear that sustainable entrepreneurship contains a value-oriented element. However, which elements play a role in the very first phase of the entrepreneurial process (i.e. idea generation) remains unclear. This raises the following research question: Which individual moral antecedents play a role in the entrepreneurial process of opportunity recognition for sustainable development?

To answer this research question, an exploratory empirical research design was used in which 96 would-be entrepreneurs were subjected to real-life decision-making processes in an online environment. Would-be entrepreneurs are defined here as those who have the intention to become a (sustainable) entrepreneur and are often still at school (i.e. Baron and Ensley, 2006; Dimov, 2007).

\section{Theoretical framework}

\subsection{Origins of opportunity recognition}

In general, three main ongoing debates about opportunity recognition can be distinguished within the literature. In this section, this study is positioned within these debates.

First of all, this study adopts the contemporary economic theory that entrepreneurial opportunities are associated with market failures (Kirzner, 1997). Nevertheless, market failures should not be confused with opportunities themselves (Grégoire et al., 2010a). Opportunities are about the possibility of acting, doing something about market failure dynamics in the hope of individual, firm, and social betterment. This is consistent with Venkataraman et al. (2012: 652) proposition that "an entrepreneurial opportunity consists of the opportunity to create future economic artefacts and as such, involves a demand side, a supply side, and the means to bring them together." This conceptualization of opportunity recognition is followed in this study. The second debate on opportunity recognition deals with the question of whether opportunities are objectively (Kirzner, 1997) or subjectively (Davidsson, 2015) perceived. It is not the aim of this study to debate the ontological nature of opportunities as fundamentally objective or subjective; rather, it follows Grégoire et al. (2010b: 118) assertion that "opportunity recognition rests on the subjective perception and interpretation of objective realities (e.g., market dynamics, new information, etc.)" The third debate focuses on the distinction between two intertwined phases of entrepreneurial action (McMullen and Shepherd, 2006; Shepherd et al., 2008). The first phase concerns the formation of the subjective belief that an opportunity exists for those with the relevant abilities and means to exploit it (third person opportunity). The second concerns an individual's evaluation of the opportunity insofar as it relates to him/ herself, that is, whether he/she has the means and motivations to act on the opportunity (first person opportunity). This study focuses on the first phase, namely, on the third person opportunity belief.

The notion of idea generation is related to the first phase of entrepreneurial action (i.e. third person opportunity). Vogel (2016) indicates that most existing opportunity recognition frameworks do not build on the logic that venture ideas and venture opportunities are distinct constructs and that opportunities are developed from an initial idea over time. Nevertheless, venture ideas and venture opportunities can be seen as two different, although closely related, concepts. Idea generation lays the foundation for opportunity recognition and is a measurable construct, whereas opportunity recognition is not easily measured. This study focuses primarily on the process of individuals recognizing opportunities by means of idea generation, as this forms an important foundation for the rest of the process. Therefore, opportunity recognition is used interchangeably with idea generation throughout the remainder of the article.

\subsection{Opportunity recognition for sustainable development}

Sustainability can be conceptualized as resulting from acting on market failures, and market failures can be seen as sources of new entrepreneurial business opportunities. Because sustainability has been acknowledged as a source of opportunities (Dean and McMullen, 2007), some research efforts have been made to a) provide an overview of the opportunity recognition process specifically for sustainable development and b) indicate those key elements that make the difference between regular opportunity recognition and opportunity recognition for sustainable development (Dean and McMullen, 2007; Patzelt and Shepherd, 2011).

One of the most widely used models of opportunity recognition for sustainable development was developed by Patzelt and Shepherd (2011). Their model describes the role of prior knowledge (of the natural and/or communal environment and of entrepreneurship) in combination with a sense of perceived threat to the environment and the level of altruism toward others as facilitators for recognizing opportunities for sustainable development. In their conceptual model (see Fig. 1), they focus on the role of knowledge and motivation as explanatory factors of opportunity recognition

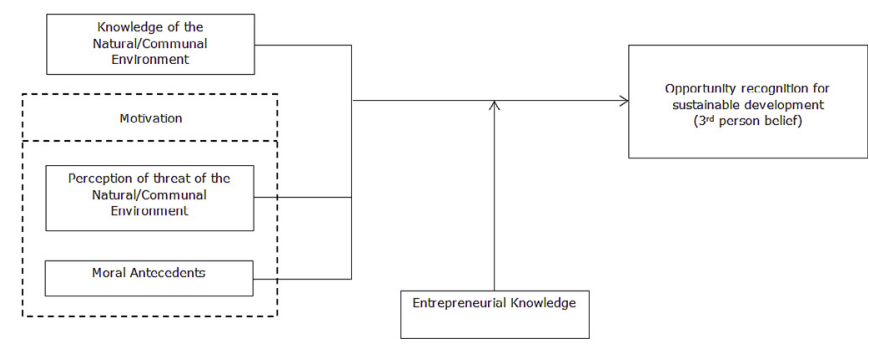

Fig. 1. Conceptual model based on Patzelt and Shepherd (2011), in which altruism towards others is replaced by the variable moral antecedents. 
for sustainable development process. Within the motivational aspect, Patzelt and Shepherd (2011) underpin the importance of altruism as a normative element in the model, but it still remains a very broad and conceptual concept. A more specific and in-depth normative element is missing and should be added to the model, given that acting upon environmental and social problems inevitably imposes moral dilemmas and that sustainability problems constitute ethical issues (Muñoz and Dimov, 2015). Dealing with sustainability is not only about applying the right formulas and policies to help improve our current wealth, but also about taking responsibility for distributing well-being, sacrifice, and risks equally between rich and poor, humans and non-humans, and present and future generations (Blok et al., 2016). The concept of sustainable entrepreneurship can therefore be characterized by its normative character. Individual ethical values and norms seem to be essential for sustainable entrepreneurship and can therefore be seen as important drivers in recognizing opportunities for sustainable development (Lans et al., 2014; Blok et al., 2016). Sustainable entrepreneurs act as moral agents facing a moral entrepreneurial imperative every time sustainability problems are considered or interpreted as venture opportunities (Muñoz and Dimov, 2015). The role of these ethical values and norms is becoming more important in current models of sustainable entrepreneurship (Blok et al., 2016) and is also confirmed in empirical research on competencies for sustainable entrepreneurship (Ploum et al., 2017). However, research on the role of normative or moral values is still in its infancy, and their actual relation to opportunity recognition for sustainable development is unclear. Therefore, new explorative empirical research could provide valuable insights into two questions. The first deals with which key elements can make a difference between regular opportunity recognition and opportunity recognition for sustainable development, and the second with whether this normative character could be one of these key elements (Dean and McMullen, 2007; Patzelt and Shepherd, 2011; Muñoz and Dimov, 2015).

Concluding, previous studies make important contributions to our understanding of the antecedents that enhance sustainable entrepreneurship and therefore also opportunity recognition for sustainable development in particular. This process is depicted in Fig. 1 and serves as an overview of the existing literature on opportunity recognition for sustainable development. It also introduces the concept of moral antecedents as an addition to the model. However, these process-level approaches do little to explain why certain individuals are more likely than others to recognize these opportunities for sustainable development and what characteristics could possibly explain these differences. Taking the individual as level of analysis, this study investigates what explains why some individuals are more likely to recognize these types of opportunities and explores the role of moral antecedents in this process. In section 2.3, these moral antecedents are introduced and further explored.

\subsection{Introducing individual moral antecedents}

Building on Patzelt and Shepherd's (2011) model, but focusing on the important role of moral norms and values in the process of recognizing opportunities for sustainable development, this study introduces three individual moral antecedents that form the focal point of this research. The three antecedents are self-transcendence values (Schwartz, 1994), pro-environmental behavior values (Dunlap et al., 2000; Shepherd et al., 2013), and moral competencies (Blok et al., 2016; Ploum et al., 2017).

Values are guides and determinants of social attitudes, ideologies, and social behavior. They are "an enduring belief that a specific mode of conduct or end-state of existence is personally or socially preferable to an opposite or converse mode of conduct or end-state of existence" (Rokeach, 1973: 5). Thus, they represent guiding principles for decision making and subsequent action (Ajzen, 1991). Values are different from attitudes in that values are universal beliefs that underlie attitudinal processes ( $\mathrm{Ng}$ and Burke, 2010). In addition, a major reason to focus on moral values is the pervasive and important influence of values on an individual's interpersonal, decision-making, and ethical behavior (Shepherd et al., 2013; Pohling et al., 2016). Furthermore, values can be considered as relatively stable during assessments as they are acquired by individuals through processes of socialization extending over many years (Grusec, 2011).

Patzelt and Shepherd (2011) underpinned the importance of altruism toward others as an important value or motivational aspect in the sustainable entrepreneurial process; the current study adds also the importance of altruism toward the environment in the combined factor called self-transcendence (Schwartz, 1994). Altruism is explained as the individual motivation to improve the welfare of another person (Penner et al., 2005: 368). Many explanations of altruism imply that individuals (consciously or nonconsciously) act altruistically because it is in their self-interest in contrast to developing purely personal gain, but altruistic action always includes some sacrifice to oneself and an intention to develop benefits for others (Penner et al., 2005). Schwartz extends this conception of feeling empathy and sympathy for others to the environment in his universal personal values theory. Here, selftranscendence is a combined factor of 'benevolence' and 'universalism'. Benevolence addresses serving and enhancing the welfare of those with whom one is in frequent personal contact (the 'ingroup'), and universalism is about understanding, appreciation, tolerance, and protection for the welfare of all people and for nature (Schwartz, 1994). The latter is in line with what is usually referred to as altruism toward others. Building on Rokeach's (1973) work on the structure of values, Schwartz (1994) developed an instrument to measure dimensions of values that are considered to be universal across all people. This study focuses only on self-transcendence values as they are a promising antecedent of sustainable opportunity recognition.

Whereas altruism and self-transcendence cover the more universal values and can be interpreted very broadly, the concept of opportunity recognition for sustainable development is rather context specific. A value-driven construct that is used more often in different kinds of sustainability-related studies is proenvironmental behavior. Pro-environmental behavior (PEB) values are considered as important predictors of sustainable opportunity recognition (Shepherd et al., 2013). Whereas Shepherd et al. (2013) focus mostly on the role of these values in moral disengagement, they underpin the importance of these values for opportunity recognition. Although PEB values are discussed in general in the literature, they are rarely specified. An exception to this is the United Nations Millennium Declaration (United Nations General Assembly, 2000), which identified the precepts of sustainable development as respect for nature, shared responsibility, freedom, equality, solidarity, and tolerance. Perceiving an opportunity that benefits the natural environment as highly attractive is likely to be consistent with these general principles. An entrepreneur with higher pro-environmental values is more likely than an entrepreneur with weaker pro-environmental values to perceive an opportunity that influences the natural environment positively.

In the field of competencies for sustainable entrepreneurship, another value-oriented construct has been distinguished as being distinctive for sustainable entrepreneurship. In this field of research, moral competencies are identified as important influencers in the sustainable entrepreneurial process. In general competencies are described as enabling successful task performance 
and problem solving with respect to real-world problems, challenges and/or opportunities on an individual level and exist of knowledge elements, skills, and attitudes (Mulder, 2014). Over the last two decades there has been a continuous search for more comprehensive conceptualizations of competence. While the previous conceptualizations focused on the job or on the characteristics of the worker, the comprehensive approach refers to the integrated and internalized capability conditional for accomplishing task performance, problem solving and functioning within a specific position and context (Mulder, 2017). From this comprehensive perspective competence is defined as "the generic, integrated and internalized capability to deliver durable effective performance in a certain professional domain, job, role, organizational context, and task situation" (Mulder, 2014, p. 111). Moral competence, in the literature used interchangeably with ethical competence, is covered mostly in the business ethics literature. In general, moral competence is described as "the sensitivity of managers and professionals to moral issues in their organizational structures followed by moral judgment and actions" (Pohling et al., 2016: 2). It can be considered as the transformation of intentional behavior to actionable behavior (Blok et al., 2016). Nevertheless, whereas Pohling et al. (2016) and Morales-Sánchez and CabelloMedina (2013) focus primarily on the ethical decision-making process and the moral competencies needed to manage this process, this research focuses on the business context of sustainable entrepreneurs and the moral competencies needed to manage this particular process. Two moral competencies contextualized within the sustainable entrepreneurial context and proven to be empirically sound are normative competence and strategic action competence (Lans et al., 2014; Ploum et al., 2017). Normative competence is described as an attribute whereby change agents are enabled to collectively map, specify, apply, reconcile, and negotiate sustainability values, principles, goals, and targets (Wiek et al., 2011). Sustainable development cannot be achieved merely through state intervention, legislation, new technologies, and efficient economies, but requires passive and active support from individuals (Blok et al., 2016). In line with this, strategic action competence is described as the ability to actively involve oneself in responsible actions to improve the sustainability of socialecological systems (Mogensen and Schnack, 2010). They both concern norms, values, and beliefs that define what is right and wrong concerning sustainability, and enable professionals to take the right decisions and behave in a responsible way (Blok et al., 2016). Furthermore, they are assumed to enable individuals to recognize those opportunities that are related to sustainable development and can be seen as discriminating factors in this process. Therefore, both competencies are taken into account as possible additional moral antecedents in the process of recognizing opportunities for sustainable development.
In conclusion, Fig. 2 depicts the model used to analyze the relationship between individual moral antecedents and opportunity recognition for sustainable development. This model is an indepth representation of the block 'Moral antecedents' from Fig. 1.

\section{Methods}

In order to answer the main research question and research the relationships as presented in the conceptual model, an explorative, yet quantitative, research design was chosen. Sections 3.1 and 3.2 describe the setting and sample, constructs and measures, and analysis of the data in more detail.

\subsection{Setting and sample}

The participants in this exploratory study were $\mathrm{N}=105$ international BSc students of a life sciences university in the Netherlands, who were following the principles of entrepreneurship course in May $2015(n=50)$ and in September $2015(n=55)$ as a free choice module in their educational program. In total, there were $\mathrm{n}=96$ valid cases; nine cases were excluded because of missing data. The questionnaires and case study assignment were administrated throughout the six weeks of class. After a short introduction in the first week of the course, in which the anonymity and confidentiality of the data were stressed and the procedure explained, the participants signed a declaration of consent.

\subsection{Constructs and measures}

A digitally scripted learning tool (Noroozi et al., 2012) was designed to actively engage would-be entrepreneurs in an online environment to critically engage in 'real-life' decision-making processes in the field of sustainable entrepreneurship. In this way, participants experienced how difficult it can be to make a trade-off between social, environmental, and economic goals and values in a business context. The core task consisted of an opportunity recognition assignment centered on a case description of an existing company. In the learning tool, the original business model of the existing company, Interface, (before it adopted a sustainability strategy) was used as a case description, and the description was anonymized. Using the Business Model Canvas (BMC) (Osterwalder and Pigneur, 2009), participants analyzed the company's case description. Participants were asked to come up with new ideas to improve the business model accordingly. These ideas were used as the main source of input for analysis. In addition to this core task, the individual moral antecedents were queried as subtasks of the digitally scripted learning tool in the first week of the course.

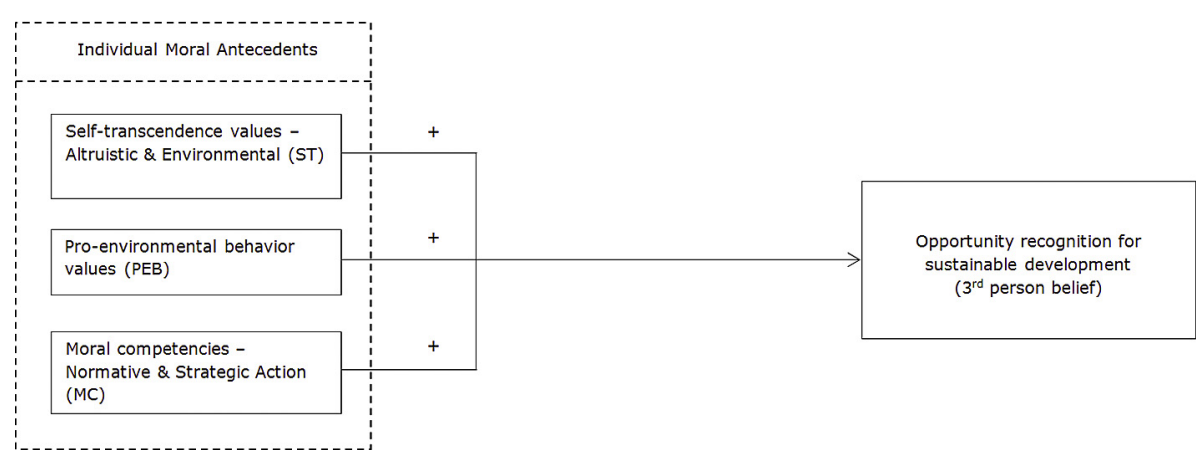

Fig. 2. Zooming in on the moral antecedents as depicted in Fig. 1 and their relation to opportunity recognition for SD. 


\subsubsection{Independent variables}

Schwartz (1994) developed an instrument to measure dimensions of values that are considered to be universal across all people. The instrument is composed of 52 value items that represent 10 value types. Respondents are asked to rate the importance of each value item on a 5-point Likert scale. The second measure used in this study is the revised version of the New Environmental Paradigm (NEP) scale (Dunlap et al., 2000; Cordano et al., 2010) to measure PEB values. The revised NEP scale contains 15 items rated on a 5-point Likert scale. Thirdly, normative competence and strategic action competence are measured by means of a competence self-report (Lans et al., 2014; Ploum et al., 2017). To measure their competencies, respondents were asked to rate themselves, on a scale of $1-10(1=$ low and $10=$ high $)$, on their perceived performance at that moment in time for an item/statement belonging to the competencies.

The complete questionnaires can be obtained from the corresponding author upon request.

\subsubsection{Dependent variable}

Opportunity recognition is measured by the number of identified ideas and by analyzing the content of these ideas. In line with other studies, it is argued here that an essential part of the opportunity recognition process is the generation of opportunity ideas: initial ideas or envisioned futures in the mind of an individual (Lumpkin and Lichtenstein, 2005; Vogel, 2016). Respondents were completely free to choose sustainable or unsustainable opportunities.

3.2.2.1. Frequency of ideas. As the number of problems identified and the number of ideas proposed can say something about a person's ability to identify opportunities, these two aspects were counted for each would-be entrepreneur. In order to identify whether a problem or idea could be considered a sustainable oneand therefore had a clear focus on the triple bottom line - the eight sustainable archetypes identified by Bocken et al. (2014) were used as indicators. The archetypes are described as follows: maximize material and energy efficiency, create value from waste, substitute with renewables and natural processes, deliver functionality rather than ownership, adopt a stewardship role, encourage sufficiency, repurpose for society/environment, and develop scaled-up solutions (Bocken et al., 2014). If an idea could be categorized within at least one of the sustainable archetypes, the idea was considered an idea related to sustainable development. Also, choosing to innovate within the environmental/societal impact block of the BMC or the value proposition block can be seen as inclining more toward an opportunity for sustainable development and was therefore taken into account $(0=$ not used/chosen, $1=$ used as first block, $2=$ used as second block, 3 = used as third block). In line with this, a score was kept of whether sustainability was mentioned in the value proposition ( $0=$ no, $1=$ yes) and whether sustainability was mentioned in the other blocks of the BMC $(0=$ not mentioned, $1=$ mentioned).

3.2.2.2. Content of ideas. Idea generation is recognized as being a domain-specific form of creativity. Creativity helps a person to come up with a new opportunity, without being stopped too much by cognition or other (rational) barriers (Corbett, 2007). Therefore, the ideas were scored on the basis of Guilford's (1967) classification and later adjusted by Baggen et al. (2016), who formulated three factors to score ideas on creativeness: fluency, elaboration, and flexibility. However, whereas Baggen et al. (2016) scored the ideas on a dichotomous (yes and no) scale, the current study used a 5point Likert scale, because the former classification led to all ideas being comprehensible and concrete.
In line with Guilford's (1967) guidelines, the ideas were scored on comprehensibility ( $1=$ totally incomprehensible, $5=$ totally comprehensible). Incomprehensible ideas were excluded from further analysis. For instance, 'offer products' was too vague to interpret in the context of sustainable development. Furthermore, the ideas were scored on concreteness: the degree to which it was possible to visualize or apply the idea ( $1=$ not concrete, 5 = concrete). For instance, 'carpooling' makes more sense than 'rearrange the whole supply chain', although the second idea contains more details. Average scores on comprehensibility and concreteness were calculated. Flexibility indicates the degree to which the participants generated ideas in different categories. Bocken et al. (2014) eight sustainable archetypes were used to categorize the ideas. For instance, 'use solar energy' and 'use energy from windmills' are both related to the category 'maximizing material and energy efficiency'. The ideas 'substitute yarn with ecofriendly alternative', and 'diversify assortment' relate to different categories, indicating a higher flexibility score. Each idea per person was scored in one or more categories.

\subsubsection{Analysis of the data}

The 96 reports in which participants identified new ideas were coded in Atlas.ti. Before the whole set of 96 reports was coded, a trial session based on 12 reports (12.5\% of the total set) was held in order to finalize the codebook. Two raters were involved in the trial session and scored all the ideas, resulting in $80 \%$ agreement on core constructs. After intense discussion, the final codebook was developed and used for the analysis of the 96 reports.

Given the explorative nature of this study, simple statistics were used to discover potential relations between the predictor (moral antecedents) and outcome (opportunities) variables. On the basis of the analysis of the coded reports, the quantified data as well as the test data were entered and analyzed in IBM SPSS Statistics 23.

\section{Results}

\subsection{Descriptive statistics: sample}

In total, 96 cases were included in the analysis. The male-female division within the dataset was $46.9 \%$ and $53.1 \%$, respectively. Most respondents were, at the time of participation, enrolled in their third year of education at the participating higher education institute (89.9\%). Of these respondents, $52.1 \%$ were following a more beta-oriented study program (natural and technical science) and $47.9 \%$ a more gamma-oriented study program (social science). Only a few respondents indicated that they already had their own company (10.6\%) versus the majority (89.4\%) who stated that they did not have their own company. Nevertheless, all respondents had the intention of becoming an entrepreneur in the future, with $76.3 \%$ of them having a score of 3 or higher, measured on a 5-point Likert scale. Also, their attitude toward entrepreneurship was positive overall, with $87.5 \%$ of the respondents scoring a 3 or higher on average. Furthermore, 36.5\% indicated that they had entrepreneurial parents, compared to $63.5 \%$ who indicated that they did not have entrepreneurial parents.

\subsection{Descriptive statistics: explanatory variables - moral antecedents}

Mean scores and Spearman correlation coefficients between the moral antecedents were calculated (Table 1) to check whether the constructs could be considered as discriminant constructs. As expected, altruism toward others and altruism toward the environment correlated highly with the combined variable selftranscendence $(r=0.812$ and $r=0.902$, both $p<0.01)$ and 
Table 1

Descriptive statistics: mean scores and correlation coefficients between moral antecedents.

\begin{tabular}{|c|c|c|c|c|c|c|c|c|c|}
\hline & M & SD & 1 & $1 \mathrm{a}$ & $1 \mathrm{~b}$ & 2 & 3 & $3 a$ & $3 b$ \\
\hline & & & \multicolumn{7}{|c|}{ Spearman correlation coefficients } \\
\hline 1. ST & 3.60 & 0.64 & - & & & & & & \\
\hline 1a. Altruism others & 3.71 & 0.73 & $0.812^{* *}$ & - & & & & & \\
\hline 1b. Altruism environment & 3.45 & 0.75 & $0.902^{* *}$ & $0.484^{* *}$ & - & & & & \\
\hline 2. PEB & 3.67 & 0.55 & $0.600^{* *}$ & $0.516^{* *}$ & $0.524^{* *}$ & - & & & \\
\hline 3. MC & 6.93 & 0.88 & $0.494^{* *}$ & $0.347^{* *}$ & $0.487^{* *}$ & $0.577^{* *}$ & - & & \\
\hline 3a. Normative & 7.32 & 1.04 & $0.442^{* *}$ & $0.313^{* *}$ & $0.430^{* *}$ & $0.462^{* *}$ & $0.861^{* *}$ & - & \\
\hline 3b. Strategic action & 6.75 & 0.91 & $0.465^{* *}$ & $0.324^{* *}$ & $0.462^{* *}$ & $0.582^{* *}$ & $0.952^{* *}$ & $0.668^{* *}$ & - \\
\hline
\end{tabular}

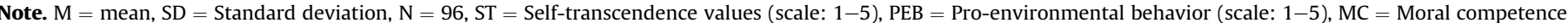
(scale: $1-10),{ }^{* *} \mathrm{p}<0.01$.

correlated moderately with each other $(r=0.484, p<0.01)$, indicating that they measure two different aspects. This also holds for the combined variable moral competence, which is composed of normative competence and strategic action competence $(r=0.861$ and $r=0.952, p<0.01$ ), with a correlation between the constructs of $r=0.668, p<0.01$. All moral antecedents correlated moderately with one another $(\mathrm{p}<0.01)$. The correlations did not exceed the threshold of $r=0.7$ and therefore did not overlap too much. The only moral antecedent that did not correlate significantly with most of the other antecedents was cognitive moral development; it correlated significantly only with self-transcendence $(r=0.16$, $p<0.01)$ and altruism toward others $(r=0.277, p<0.01)$.

\subsection{Descriptive statistics: dependent variable - idea generation scores}

As explained, opportunity identification was measured through an idea generation assignment. In total, 249 problems were identified, of which 123 related to sustainable development (49.4\%). On average, respondents were able to identify 2.6 problems in general, and 1.3 problems related to sustainable development (50\%). In total, 29 respondents $(30.2 \%)$ did not identify any problems related to sustainable development. The other 67 respondents $(69.8 \%)$ did identify problems in the business model that could relate to sustainable development, ranging from one identified problem to seven problems in total. Regarding the number of identified ideas, in total 427 ideas were generated, of which 200 related to sustainable development (46.8\%). On average, respondents identified 4.5 ideas in general and 2.1 ideas specifically related to sustainable development (46.6\%). Sixteen of the respondents (16.7\%) did not generate any ideas related to sustainable development; the other 80 respondents $(83.3 \%)$ did identify new ideas ranging from one idea to nine different ideas per respondent. The results of the correlation analysis indicate that the number of identified problems related to sustainable development correlated strongly to the number of identified ideas for sustainable development $(r(94)=0.451, p<0.05)$

Besides the number of identified problems and ideas, choosing to innovate within the environmental impact block of the BMC and within the value proposition block, and mentioning sustainability in the latter and throughout the BMC, were coded and scored for analysis. Table 2 provides an overview of the scores on these elements. Choosing to innovate in the value proposition block does not show a significant relation with the number of identified ideas for sustainable development. However, choosing to innovate within the environmental impact block does show a strong correlation with the number of identified ideas for sustainable development $(r(94)=0.523, p<0.05)$. Not all business model innovations (i.e. new ideas) within the value proposition are related to sustainability, whereas the ideas within the environmental/societal impact block are. Only 10 respondents chose to mention sustainability in the value proposition block; this could explain these results.

\subsection{Descriptive statistics: dependent variable - content of the ideas}

Examination of the generated ideas related to sustainable development and the scores on the content of those ideas reveals that all ideas are scored as comprehensible and concrete, with average scores of 3.50 and 2.05, respectively (Table 3 ). This means that on average the respondents scored just above the mid-point for comprehensibility and provided only some details, but mostly just mentioned the idea. On average, the flexibility score was 0.21 , with 0.13 being the lowest score and 0.50 the highest. Nevertheless, the range of the scores on the content of the ideas varied extremely between the ideas. To illustrate this: the three highest scoring ideas on flexibility (number of categories), comprehensibility, and concreteness were 'use elephant grass as material for carpets' (scores of 3, 5, and 5), 'replace yarn with Sorona Fibres' (scores of 2, 4 , and 5) and 'store energy with compressed air energy storage' (scores of 2, 4, and 4). The three lowest scoring ideas were: 'use organic materials' (scores of 1, 2, and 1), 'research glue' (scores of 1 , 2 , and 1) and 'use less nylon' (scores of 1,2, and 1). However, this classification of highest and lowest scoring ideas does not say anything about the feasibility or innovativeness of the ideas.

\subsection{Testing: the relation between moral antecedents and opportunity recognition for sustainable development}

First, when the relation between the number of identified ideas for sustainable development and the four moral antecedents was tested, significant results for PEB scores $(r(94)=0.213, p<0.05)$ and moral competence as a composite construct $(r(94)=0.225$, $p<0.05)$ were found. Normative competence $(r(94)=0.215$, $p<0.05)$ and strategic action competence $(r(94)=0.200, p<0.05)$ as separate antecedents also had a significant correlation with the number of identified ideas for sustainable development. In other words, the higher the score on PEB values or on moral competencies, the more ideas for sustainable development were identified. No significant correlations were found between number of ideas and the moral antecedent self-transcendence. Also, when the separate elements of self-transcendence - consisting of altruism toward others and altruism toward the environment - were examined, no significant correlations were found. Second, when the relation between the moral antecedents and the content of the ideas for sustainable development were examined, the correlation analysis showed no significant results either. There were no significant correlations between the scores on the three individual moral antecedents and the content of the ideas as measured by flexibility, comprehensibility, and concreteness. In the process of looking for explanations for these results, scatterplots of the 
Table 2

Descriptive statistics: frequencies of indicators of Business Model Canvas (BMC).

\begin{tabular}{|c|c|c|c|}
\hline Variable & Category & Frequency & Percent \\
\hline \multirow[t]{4}{*}{ Priority environmental impact block } & Not chosen & 31 & 32.3 \\
\hline & Used as first block & 25 & 26.0 \\
\hline & Used as second block & 19 & 19.8 \\
\hline & Used as third block & 21 & 21.9 \\
\hline \multirow[t]{4}{*}{ Priority value proposition block } & Not chosen & 69 & 71.9 \\
\hline & Used as first block & 16 & 16.7 \\
\hline & Used as second block & 5 & 5.2 \\
\hline & Used as third block & 6 & 6.3 \\
\hline \multirow[t]{2}{*}{ Sustainability used in value proposition block } & No & 86 & 89.6 \\
\hline & Yes & 10 & 10.4 \\
\hline \multirow[t]{2}{*}{ Sustainability mentioned throughout BMC } & No & 85 & 88.5 \\
\hline & Yes & 11 & 11.5 \\
\hline
\end{tabular}

Table 3

Descriptive statistics: average scores of content measures.

\begin{tabular}{lll}
\hline & Range & Average score \\
\hline Flexibility score (with maximum score of 1) & $0.13-0.50$ & 0.21 \\
Comprehensibility (with maximum score of 5) & $1.67-4.00$ & 3.05 \\
Concreteness (with maximum score of 5) & $1.00-5.00$ & 0.08 \\
\hline
\end{tabular}

correlations were analyzed. These scatterplots showed a large concentration in the middle, with on both ends of the line some big differences in the scores on the moral antecedents between high and low scoring ideas on the content measures. When these extremes (in this case the highest and lowest scoring ideas for sustainable development) were further examined, an indication for differences on the scores on the moral antecedents was found (see Table 4). It appears that, for the highest scoring ideas on the three content measures, the corresponding respondents scored higher on average on the moral antecedents than the average of the whole sample. Similarly, for the respondents with the lowest scoring ideas on the three content measures, the scores on the four moral antecedents were lower on average than the average of the whole sample. Comparable results were found on examination of the high scoring individuals on the moral antecedents: top scoring individuals on the moral antecedents scored higher on the content measures. To test whether these extreme cases were not merely outliers and therefore should be excluded from the analysis, the outlier labelling rule and one sample t-tests were performed on the content measures as well as on the moral antecedents. The tests under the Tukey outlier labelling rule resulted in finding no significant outliers within the data. The one sample t-tests were not significant either; this in general means that there was no specific mean for the whole population. Specifically, these results indicate that the extreme cases were significantly different from the group average and should therefore be considered as valid data points and not as outliers.

To sum up, although not statistically significant, there are reasons for assuming that there is a relation between the moral antecedents and the content of the identified ideas for sustainable development. The analysis of the extreme cases clearly suggests that there is some kind of threshold value that can be considered as a tipping point for the influence of the moral antecedents on the content of the identified ideas.

\section{Discussion}

This research tries to unravel the initial phase in sustainable entrepreneurship by analyzing the relation between moral antecedents and opportunity recognition for sustainable development. In this study, opportunity recognition is measured by identifying (business) ideas for sustainable development. The analysis by means of regression showed that two of the three moral antecedents have a positive and significant relation with the number of identified ideas for sustainable development. These two moral antecedents are pro-environmental behavior values and moral competencies. The other moral antecedent, labeled as selftranscendence, did not relate significantly with the number of identified ideas for sustainable development. This answers the main research question: Which individual moral antecedents play a role in the entrepreneurial process of opportunity recognition for sustainable development?

Pro-environmental behavior values and moral competencies can be seen as important moral antecedents in the process of recognizing opportunities for sustainable development. In addition, the results show that the number of identified problems for sustainable development is a significantly good predictor of the number of identified ideas for sustainable development. Another

Table 4

Scores on moral antecedents of the three highest and the three lowest scoring ideas on the three content measures.

\begin{tabular}{|c|c|c|c|c|}
\hline & Respondent-ID and corresponding idea & Self-transcendence & Pro-environmental behavior & Moral competence \\
\hline Group average & & 3.6 & 3.7 & 6.9 \\
\hline \multirow[t]{3}{*}{ Ideas that score high on the 3 content measures } & 12 - Elephant & 4.7 & 4.5 & 8.7 \\
\hline & 29 - CAES & 4.0 & 3.7 & 7.3 \\
\hline & 35 - Sorona & 4.3 & 4.0 & 8.3 \\
\hline \multirow[t]{3}{*}{ Ideas that score low on the 3 content measures } & 20 - Organic & 3.4 & 3.5 & 6.8 \\
\hline & 27 - Glue & 3.0 & 3.5 & 6.2 \\
\hline & 65 - Nylon & 2.6 & 2.9 & 6.0 \\
\hline
\end{tabular}

Note. The three content measures are comprehensibility, concreteness and flexibility. The ideas are described in detail in section 3.2.2. 
positive result of this study is the relation between choosing to innovate within the environmental/societal impact block of the BMC and the number of ideas for sustainable development identified. The original BMC does not include this block, but assumes that sustainability-related topics can be integrated in the other blocks. Nevertheless, more and more research on sustainable business models is being conducted, as sustainability is becoming a more important factor for businesses (Abdelkafi and Täuscher, 2016; Joyce and Paquin, 2016). Research varies from a completely new system dynamics approach (Abdelkafi and Täuscher, 2016) to 'simply' adding new elements to existing models (Joyce and Paquin, 2016). Because of the wide variety of orientations, there is still no consensus on how sustainability should be incorporated in existing business model tools. Providing concrete answers to this discussion is beyond the scope of this research. However, the results do suggest that making the environmental/societal impact of the business model visible within the BMC in the form of an additional block leads to the identification of more ideas for sustainable development.

Finally, the results of this study have led to a re-evaluation of the conceptual model depicted in Fig. 1. The refined model of opportunity recognition for sustainable development is presented in Fig. 3.

The relation between self-transcendence (i.e. altruism toward others) and opportunity recognition for sustainable development was not confirmed in this study. Most of the literature on sustainable or social entrepreneurship emphasizes the importance of altruism in the entrepreneurial process (Patzelt and Shepherd, 2011). However, these studies are usually conceptual in nature, whereby altruism is often seen as an intrinsic motivation to do good and help others. In studies of sustainable entrepreneurship, altruism is usually explained by empathy and sympathy toward others (Patzelt and Shepherd, 2011). As appears from the results, a general moral orientation or sensitivity toward environmental issues, operationalized in this study by altruistic values, is not correlated with the recognition of sustainable entrepreneurial opportunities. A possible explanation for this could be that these altruistic values cover mostly the human aspects of morality, like empathy and sympathy toward others, whereas recognizing opportunities for sustainable development deals mostly with the more environmental aspects of morality. This is also in line with research on distal and proximal constructs, which are common in the psychology domain (Rauch and Frese, 2007). It could be that altruism can be considered as a more general or distal construct that influences a more specific or proximal construct (for instance moral competencies), which in turn relates to an outcome variable. The relation of self-transcendence with recognizing opportunities could therefore possibly be considered as indirect, but more research is needed to assess whether this is actually the case.

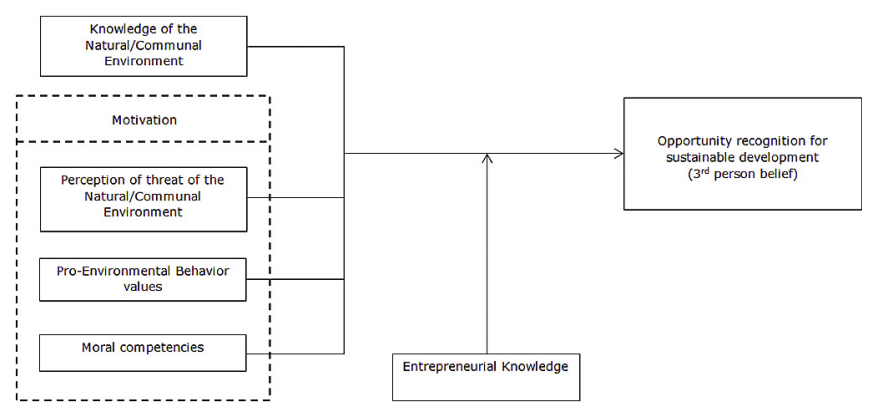

Fig. 3. Refined conceptual model of opportunity recognition for sustainable development.
Another important element of this study relates to the content of the ideas. It is not only the ability to identify ideas for sustainable development that is an important indication of opportunity recognition; the content of the ideas can also say something about whether an idea has more or less potential to become a first person opportunity. Nevertheless, the results found in this study do not provide sufficient significant backup for a possible relation between the moral antecedents and the content of the ideas for sustainable development. This could have to do with the majority of the sample scoring an average score of 3 on the comprehensibility and concreteness measures, as it remains hard to classify the ideas. Furthermore, the classification based on the work of Guilford (1967) and Baggen et al. (2016) needs to be further strengthened and validated in the field of opportunity recognition, as it is based on creativity measures. As a result of the clustering of scores in the middle, the cases on the far ends of the spectrum were analyzed in more detail. Examination of these extremely high and low scores on the content measures reveals that those respondents also score higher or lower on average on the moral antecedents. Also, examination of the extreme scores on the moral antecedents reveals that those respondents who score high on the moral antecedents also score better on average on the content measures than the respondents who score lower on the moral antecedents. In other words, although not statistically significant, there are reasons for assuming that there is a relation between the moral antecedents and the content of the identified ideas for sustainable development. There seems to be a threshold, given the extreme scores of the moral antecedents and their relation to the content of the identified ideas. Identifying the exact threshold is beyond the scope of this study but has led to a proposition for future research: the higher the scores on the moral antecedents, the better the content of the ideas.

Although the results of this study are promising, some limitations have to be mentioned. First, the data were collected among would-be entrepreneurs, (i.e. students with the intention of becoming a [sustainable] entrepreneur), and at only one higher education institute. Future research could for instance focus on conducting focus groups with nascent and established sustainable entrepreneurs or on testing the model with these two groups to examine whether the moral antecedents could also be supportive in the entrepreneurial process. Second, the study focuses on the recognition of sustainable development opportunities for someone (third person opportunities), but it does not investigate individuals' assessments of whether these opportunities represent opportunities for themselves (and thus, their intentions and decisions to exploit those opportunities [first-person opportunities]). These are distinct and subsequent steps in models of entrepreneurial action (Shepherd et al., 2008). Third, it is acknowledged that many factors beyond the moral antecedents - such as knowledge (Patzelt and Shepherd, 2011), the individuals' networks (Ozgen and Baron, 2007), and cognitive structures (Baron and Ensley, 2006) - may influence individuals' recognition of sustainable development opportunities. Investigating all these factors is beyond the scope of this study but could be addressed in future empirical research on opportunity recognition for sustainable development. Testing the complete model, with all subsequent blocks and underlying interactions, is the next step that needs to be taken.

\section{Conclusion}

In a world in which global climate disruption, ever-increasing populations, and massive extinctions of biodiversity are recognized and acknowledged, there is a need for individuals who are able to deal with these challenges through their entrepreneurial behavior. This study has shown that pro-environmental behavior 
values and moral competencies are important elements in the very early stage of recognizing opportunities for sustainable development.

Knowing what kind of moral antecedents enable future change agents to deal with these complex problems and being able to identify opportunities for these problems, helps higher education institutes to adjust and reframe their education program accordingly. Recent approaches highlight the importance of entrepreneurship education to inspire and build awareness of the opportunities inherent in the sustainability arena for self-interest and to benefit diverse stakeholders (Kuckertz and Wagner, 2010). However, there are only a few studies that investigate the learning processes, learning inputs and outputs of nascent sustainable entrepreneurs in specific educational interventions. In this process it is important to keep track of the moral competencies that are important for sustainable entrepreneurship and to foster them within the teaching cases. Lackéus (2015) provides stepping stones for teaching cases that enable learning by doing and the possibility to integrate moral obligations into entrepreneurial practices. Examples are the Business Model Canvas and the Lean start-up (e.g. Lackéus, 2015). Sustainability is therefore not just an add-on to the entrepreneurship programs that already exist. It has to be implemented at the core of entrepreneurship education, focusing on the development of moral competencies and teaching methods that enable students to move away from a sole focus on profit maximization but leaves room for the triple bottom line. This study provides stepping stones for future research on the implementation of moral antecedents in entrepreneurship education by using the Business Model Canvas. Furthermore, the results of this study support starting sustainable entrepreneurs in their entrepreneurial processes by focusing on the development of moral antecedents during this very early stage of the entrepreneurial process. More attention should be paid to the development of moral competencies within business acceleration programs, business incubators, and professional education programs. Altogether, at this point, the refined framework for recognizing opportunities for sustainable development (Fig. 3) provides researchers as well as teachers and sustainable entrepreneurs with stepping stones to further enhance sustainable entrepreneurship.

\section{Declaration of interest}

All authors declare that there are no conflicts of interest.

\section{Funding}

This research did not receive any specific grant from funding agencies in the public, commercial, or not-for-profit sectors.

\section{References}

Abdelkafi, N., Täuscher, K., 2016. Business models for sustainability from a system dynamics perspective. Organ. Environ. 29 (1), 74-96.

Ajzen, I., 1991. The theory of planned behavior. Organ. Behav. Hum. Decis. Process. 50 (2), 179-211.

Baggen, Y., Kampen, J., Naia, A., Biemans, H.J.A., Lans, T., Mulder, M., 2016. Development and application of the opportunity identification competence assessment test (OICAT) in higher education. Innovat. Educ. Teach. Int. 1-11.

Baron, R.A., Ensley, M.D., 2006. Opportunity recognition as the detection of meaningful patterns: evidence from comparisons of novice and experienced entrepreneurs. Manag. Sci. 52, 1331-1344.

Blok, V., Gremmen, B., Wesselink, R., 2016. Dealing with the wicked problem of sustainability. Bus. Prof. Ethics J. https://doi.org/10.5840/bpej201621737.

Bocken, N.M.P., Short, S.W., Rana, P., Evans, S., 2014. A literature and practice review to develop sustainable business model archetypes. J. Clean. Prod. 65, 42-56.

Corbett, A.C., 2007. Learning asymmetries and the discovery of entrepreneurial opportunities. J. Bus. Ventur. 22 (1), 97-118.

Cordano, M., Welcomer, S., Scherer, R., Pradenas, L., Parada, V., 2010. Understanding cultural differences in the antecedents of pro-environmental behavior: a comparative analysis of business students in the United States and Chile. J. Environ. Educ. 41 (4), 224-238.

Davidsson, P., 2015. Entrepreneurial opportunities and the entrepreneurship nexus: a re-conceptualization. J. Bus. Ventur. 30, 674-695.

Dean, T.J., McMullen, J.S., 2007. Toward a theory of sustainable entrepreneurship: reducing environmental degradation through entrepreneurial action. J. Bus. Ventur. 22, 50-76.

Dimov, D., 2007. Beyond the single-person, single-insight attribution in understanding entrepreneurial opportunities. Entrepreneursh. Theory Pract. 31, $713-731$.

Dunlap, R.E., Van Liere, K.D., Mertig, A.G., Jones, R.E., 2000. New trends in measuring environmental attitudes: measuring endorsement of the new ecological paradigm: a revised NEP scale. J. Soc. Issues 56 (3), 425-442.

Grégoire, D.A., Barr, P.S., Shepherd, D.A., 2010a. Cognitive processes of opportunity recognition: the role of structural alignment. Organ. Sci. 21 (2), 413-431.

Grégoire, D.A., Shepherd, D.A., Schurer Lambert, L., 2010b. Measuring opportunityrecognition beliefs: illustrating and validating an experimental approach. Organ. Res. Meth. 13 (1), 114-145.

Grusec, J.E., 2011. Socialization processes in the family: social and emotional development. Annu. Rev. Psychol. 62, 243-269.

Guilford, J.P., 1967. Potentiality for creativity. In: Gowan, J.C., Khatena, J., Torance, E.P. (Eds.), Creativity: its Educational Implication. Kendall Hunt, Dubuque, IA.

Joyce, A., Paquin, R.L., 2016. The triple layered business model canvas: a tool to design more sustainable business models. J. Clean. Prod. 135, 1474-1486.

Kirzner, I.M., 1997. Entrepreneurial discovery and the competitive market process: an Austrian approach. J. Econ. Lit. 35 (1), 60-85.

Kuckertz, A., Wagner, M., 2010. The influence of sustainability orientation on entrepreneurial intentions-Investigating the role of business experience. J. Bus. Ventur. 25 (5), 524-539.

Lackéus, M., 2015. Entrepreneurship in Education: what Why, when How. Entrepreneurship360 background paper. http://www.oecd.org/cfe/leed/BGP Entrepreneurship-in-Education.pdf. (Accessed 10 August 2017).

Lans, T., Blok, V., Wesselink, R., 2014. Learning apart together: towards an integrated framework for sustainable entrepreneurship competence in higher education. J. Clean. Prod. 62, 37-47.

Lumpkin, G.T., Lichtenstein, B.B., 2005. The role of organizational learning in the opportunity-recognition process. Entrepreneursh. Theory Pract. 29 (4), $451-472$.

Morales-Sánchez, R., Cabello-Medina, C., 2013. The role of four universal mora competencies in ethical decision-making. J. Bus. Ethics 116 (4), 717-734.

McMullen, J.S., Shepherd, D.A., 2006. Entrepreneurial action and the role of uncertainty in the theory of the entrepreneur. Acad. Manag. Rev. 31, 132-152.

Mogensen, F., Schnack, K., 2010. The action competence approach and the 'new' discourses of education for sustainable development, competence and quality criteria. Environ. Educ. Res. 16, 59-74.

Mulder, M., 2014. Conceptions of professional competence. In: Billett, S., Harteis, C. Gruber, H. (Eds.), International Handbook on Research into Professional and Practice-based Learning. Springer, Dordrecht, pp. 107-137.

Mulder, M., 2017. Competence-based Vocational and Professional Education. Bridging the Worlds of Work and Education. Springer International, Cham, Switzerland.

Muñoz, P., Dimov, D., 2015. The call of the whole in understanding the development of sustainable ventures. J. Bus. Ventur. 30 (4), 632-654.

Ng, E.S., Burke, R.J., 2010. Predictor of business students' attitudes toward sustainable business practices. J. Bus. Ethics 95 (4), 603-615.

Noroozi, O., Weinberger, A., Biemans, H.J., Mulder, M., Chizari, M., 2012. Argumentation-based computer supported collaborative learning (ABCSCL): a synthesis of 15 years of research. Educ. Res. Rev. 7 (2), 79-106.

Osterwalder, A., Pigneur, Y., 2009. Business Model Creation. Modderman Drukwerk, Amsterdam, The Netherlands.

Ozgen, E., Baron, R.A., 2007. Social sources of information in opportunity recognition: effects of mentors, industry networks, and professional forums. J. Bus. Ventur. 22, 174-192.

Patzelt, H., Shepherd, D.A., 2011. Recognizing opportunities for sustainable development. Entrepreneursh. Theory Pract. 35 (4), 631-652.

Penner, L.A., Dovidio, J.F., Piliavin, J.A., Schroeder, D.A., 2005. Prosocial behavior: multilevel perspectives. Annu. Rev. Psychol. 56, 365-392.

Ploum, L., Blok, V., Lans, T., Omta, O., 2017. Toward a validated competence framework for sustainable entrepreneurship. Organ. Environ. https://doi.org $10.1177 / 1086026617697039$.

Pohling, R., Bzdok, D., Eigenstetter, M., Stumpf, S., Strobel, A., 2016. What is ethical competence? The role of empathy, personal values, and the five-factor model of personality in ethical decision-making. J. Bus. Ethics 137 (3), 449-474.

Rauch, A., Frese, M., 2007. Born to be an entrepreneur? Revisiting the personality approach to entrepreneurship. In: Baum, J.R., Frese, M., Baron, R.A. (Eds.), The Psychology of Entrepreneurship. Lawrence Erlbaum, Mahwah, NJ, pp. 41-65.

Rokeach, M., 1973. The Nature of Human Values. Free Press, New York.

Schaltegger, S., Wagner, M., 2011. Sustainable entrepreneurship and sustainability innovation: categories and interactions. Bus. Strategy Environ. 20, 222-237.

Schwartz, S.H., 1994. Are there universal aspects in the structure and contents of human values? J. Soc. Issues 50 (4), 19-45.

Shane, S., 2000. Prior knowledge and the discovery of entrepreneurial opportunities. Organ. Sci. 11, 448-469.

Shane, S., Venkataraman, S., 2000. The promise of entrepreneurship as a field of research. Acad. Manag. Rev. 25, 217-226. 
Shepherd, D.A., McMullen, J.S., Jennings, P.D., 2008. The formation of opportunity beliefs: overcoming ignorance and reducing doubt. Strateg. Entrepreneursh. J. 1, 75-95.

Shepherd, D.A., Patzelt, H., Baron, R.A., 2013. "I care about nature, but...": disengaging values in assessing opportunities that cause harm. Acad. Manag. J. 56 (5), $1251-1273$.

Swart, R.J., Raskin, P., Robinson, J., 2004. The problem of the future: sustainability, science and scenario analysis. Glob. Environ. Change 14 (2), 137-146.

United Nations, 2016. United Nations: the Sustainable Development Goals Report 2016. http://www.un.org.lb/Library/Assets/The-Sustainable-DevelopmentGoals-Report-2016-Global.pdf. (Accessed 10 August 2017).
United Nations General Assembly, 2000. United Nations Millennium Declaration. http://www.un.org/millennium/declaration/ares552e.htm. (Accessed 10 August 2017).

Venkataraman, S., Sarasvathy, S.D., Dew, N., Foster, W.R., 2012. Reflections on the 2010 AMR decade award: whither the promise? Moving forward with entrepreneurship as a science of the artificial. Acad. Manag. Rev. 37, 21-33.

Vogel, P., 2016. From venture idea to venture opportunity. Entrepreneursh. Theory Pract. https://doi.org/10.1111/etap.12234.

Wiek, A., Withycombe, L., Redman, C.L., 2011. Key competencies in sustainability: a reference framework for academic program development. Sustain. Sci. 6, 203-218. 